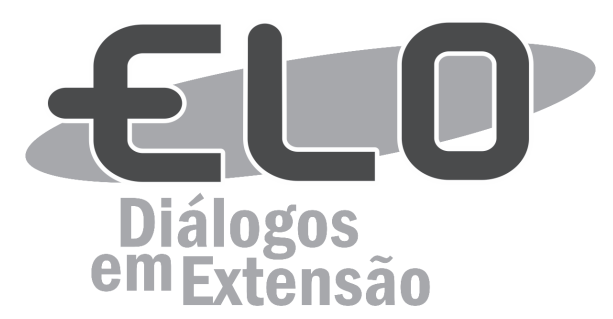

\title{
Contradições da modernidade no processo de des/re/ territorialização do lugar: o caso dos atingidos pela construção da Hidrelétrica Candonga
}

\author{
Fabiane Aparecida Silva Bortone ${ }^{1}$, Marcia P. Ludwig르, Karine Diniz Xavier ${ }^{3}$
}

\begin{abstract}
Resumo: Este artigo apresenta como a construção de empreendimentos hidrelétricos considerados "projetos de desenvolvimento e progresso" é capaz de promover transformação social causando impactos ambientais e sociais na região de implantação. Para tanto, apresenta-se a análise de um caso específico de deslocamento/ reassentamento de famílias atingidas, o da Hidrelétrica de Candonga, Zona da Mata mineira. O estudo fez-se a partir das perspectivas das famílias atingidas, por meio de entrevistas semiestruturadas e imersão em campo. Como em todo processo de implantação de projetos de barragens, o deslocamento é sempre permeado de conflitos, representados por interesses antagônicos: empreendedores e atingidos. O resultado evidenciou que implantar esses projetos gera consequências muito maiores do que aquelas previstas nos estudos de impacto. Esses projetos rompem com costumes, práticas sociais e modos de vida, em razão da apropriação do espaço para fins particulares.
\end{abstract}

Palavras-chave: Hidrelétricas. Conflitos socioambientais. Deslocamento/reassentamento.

Área Temática: Meio Ambiente e Ruralidades.

Contradictions of modernity in the Des / Re-territorialization process of place: the case of those affected by the construction of UHE Candonga

Summary: This paper shows how the construction of hydroelectric projects considered "development projects and progress" are able to promote social change causing environmental and social impacts in the region of deployment. For that we present the analysis of a specific case of displacement/resettlement of affected families, the case of hydroelectric Candonga, Mata Mining Zone. The study was done from the perspectives of affected families built through semi-structured interviews and field submersion. As in any process of implementation of dam projects, the offset is always permeated by conflicts, represented by antagonistic interests: entrepreneurs and achieved. The result shows that the implementation of these projects generate much greater consequences than those envisaged in their impact studies. These designs break with customs, social practices and ways of life due to the appropriation of space for private purposes.

Keywords: Hydroelectric. Environmental conflicts. Displacement/resettlement.

\section{Las contradicciones de la modernidad en el proceso de Des / Re-territorialización del lugar: el caso de los afectados por la construcción de la UHE Candonga}

Resumen: El artículo muestra como la construcción de hidroeléctricas consideradas "proyectos de desarrollo y progreso" son capaces de promover el cambio social causando impactos ambientales y sociales en la región de implantación. Por lo que se presenta el análisis de un caso específico de desalojo/reubicación de las familias afectadas, en el caso de la hidroeléctrica Candonga, Zona da Mata Minera. El estudio se hace a partir de las

${ }^{1}$ Universidade Federal de Viçosa - campus Florestal. Técnica Administrativa. E-mail: fabiane.bortone@ufv.br

${ }^{2}$ Universidade Federal de Viçosa - campus Viçosa. Professora do Magistério Superior.

${ }^{3}$ Universidade Federal de Viçosa - campus Florestal. Professora do Ensino Básico, Técnico e Tecnológico. 
perspectivas de esas familias a través de entrevistas semi-estructuradas y exploración en campo. Al igual que en cualquier proceso de implementación de proyectos de presas, el desplazamiento esta siempre lleno de conflictos, representados por intereses antagónicos: empresarios y afectados. El resultado muestra que la implementación de estos proyectos genera consecuencias mucho mayores que las previstas en los estudios de impacto. Estos proyectos rompen las costumbres, prácticas sociales y modos de vida en función de la apropiación del espacio con fines particulares.

Palabras clave: Hidroeléctricas. Conflictos ambientales. El desplazamiento / reasentamiento.

\section{Introdução}

Este estudo se insere nas discussões acerca da implantação de usinas hidrelétricas no contexto da modernização capitalista. O modelo econômico vigente, diante do crescente processo de produção e consumo, tem como pressuposto a demanda cada vez maior de energia. No caso do Brasil, a construção de hidrelétricas tem-se apresentado como a alternativa, historicamente, mais utilizada para se produzir energia elétrica. Contudo, são inquestionáveis os impactos ambientais e sociais resultantes de tais empreendimentos, o que faz com que pesquisadores do Brasil e de diferentes países se dediquem a essa temática. Dentro dessa perspectiva, este estudo buscou, a partir da pesquisa realizada com os atingidos pela hidrelétrica de Candonga, na Zona da Mata mineira, apresentar as contradições inerentes ao processo de construção de empreendimentos hidrelétricos, no sentido de evidenciar as transformações ocorridas após os processos de deslocamento compulsório e reassentamento de atingidos.

Nas últimas décadas, observou-se a implantação de novos modelos produtivos, novas formas de organização do trabalho e inovações técnico-científicas advindas das mudanças relacionadas com as formas de exploração do trabalho, de produção e apropriação da natureza propostas pelo atual modo de produção capitalista. Essa "reestruturação produtiva" é resultado da evolução histórica do capitalismo, que contém as contradições sociais inerentes à "crise estrutural do capital" (MESZÁROS, 2002) e garante novas bases de produção e reprodução econômica, que vai além das formas existentes de controle sobre o trabalho e sobre a natureza. Tal propósito visa manter o movimento incessante de expansão e acumulação do capital.

Diante desse processo, buscou-se destacar um novo modo de controle e domínio sobre a natureza, o social e o cultural, que está diretamente relacionada à reprodução ampliada do capital, ou seja, os processos de ocupação do solo e de valorização e acumulação de riqueza socialmente produzida. A exploração intensiva e destrutiva da natureza pela ordem social do capital projeta não apenas uma forma degradante de existência social e econômica, mas coloca em discussão questões que permeiam as temáticas em torno da sua própria sustentabilidade e do processo de permanência e reprodução da humanidade no planeta. Com esses processos ainda se identifica a formação de conflitos decorrentes das relações de dominação, que se perpetuam no sistema capitalista e, de forma mais geral, na sociedade.

A produção de energia está diretamente relacionada a essa expansão e manutenção do sistema capitalista. A energia tornou-se mercadoria, cujo acesso tem sido determinado e direcionado pelas lógicas do mercado. A hidreletricidade, considerada prioritária no Brasil, responde por mais de $90 \%$ da matriz energética nacional (BENJAMIN e RIBEIRO, 2004). Isso se deve, sobretudo, ao alto potencial hidráulico do país (260.000 MW) e à prevalência de interesses mercadológicos, subsidiados pela ação do Estado. Da energia produzida no país, grande parte vai para as indústrias chamadas eletrointensivas, que têm como característica serem grandes consumidoras de energia, como as que trabalham com alumínio, celulose, cimento, mineração etc.

O parque gerador brasileiro há muitos anos é essencialmente hidrelétrico. $\mathrm{O}$ baixo custo dessa energia aliada à riqueza natural hidrográfica levou o Brasil a ter uma posição de destaque em geração de energia hidrelétrica no cenário mundial (SILVEIRA; REIS, 2001). Segundo o Relatório do Banco Mundial (2008), as usinas hidrelétricas continuarão a desempenhar papel predominante na matriz elétrica brasileira, estimando-se que, em 2015, serão responsáveis por aproximadamente $75 \%$ da eletricidade no país. Essa predominância é determinada principalmente pelo fato de o Brasil possuir um dos maiores potenciais hidrelétricos no mundo: um total de $260 \mathrm{mil} \mathrm{MW}$, dos quais pouco mais de $30 \%$ estão em operação ou construção (BRASIL, 2008).

Segundo o relatório da Comissão Mundial de Barragens, publicado em novembro de 2000, World Commission on Dams (WCD), mais de 800.000 barragens já foram construídas no planeta; entre essas, 45 mil são de grande porte. Além disso, cerca de 1.600 barragens estão em processo de construção em 
todo o mundo, em um negócio que movimenta US\$ 50 bilhões anuais. Dessas, mais de 650 serão construídas no Brasil (MAB, 2007) e, consequentemente, mais de 1milhão de pessoas serão expropriadas e expulsas de suas terras, assim como, causará grande impacto na biodiversidade (ZHOURI et al., 2005). Não obstante aos graves impactos socioambientais e culturais, o uso dessas barragens tem sido naturalizado frente aos grandes efeitos mascarados pelo discurso das energias renováveis e de produção limpa.

Nesse ínterim, a energia vem sendo tratada como essencial ao desenvolvimento do país e de uso coletivo/público, representações essas que ocultam e mantêm as formas de apropriação privada e desigual dos recursos naturais e as contradições e o antagonismo de interesses. Diante desse processo de acumulação de capital, diferentes atores passam a compor o cenário estratégico de mercado em que os interesses globais perpetuam sobre o local, condicionando o social, ambiental e cultural à esfera econômica de desenvolvimento e progresso, essencial ao crescimento do país.

Esse discurso traz embutido a ideia de que o progresso tem seus custos e que alguém deve pagar por eles; ou seja, os prejuízos existirão e representarão a cota necessária ao desenvolvimento: "um Estado capitalista e moderno pode respeitar as diferenças culturais na medida em que não sejam obstáculos ao desenvolvimento, à modernidade" (Catullo apud LUDWIG, 2003, p. 22).

\begin{abstract}
Se não examinássemos a produção do espaço sob o enfoque de suas contradições, não recuperaríamos o sentido deste momento na história humana e, por outro lado, sua singularidade. Do ponto de vista das contradições, a crise e o movimento ganham existência, sob a aparência da consolidação de um determinado modo de interferência humano, poderoso e inconteste (DAMIANI, 2001, p. 50).
\end{abstract}

O foco dessa análise está nas contradições inerentes aos processos de deslocamento compulsório e reassentamento dos atingidos por empreendimentos hidrelétricos. Especificamente, dirigiu-se o olhar para o caso da hidrelétrica de Candonga, na Zona da Mata mineira e para os conflitos que engendraram os processos de reprodução social no/ do espaço e de apropriação material/natural e simbólica, resultado da passagem abrupta de uma sociedade com características rurais para uma sociedade mercantilizada e monetarizada.

Ainda que o trabalho tenha analisado um caso específico, esse evidenciou a necessidade e importância de que seus resultados, assim como de outros já realizados, extrapolassem a academia e passassem a constituir objeto de consulta para os projetos de desenvolvimento que pressuponham o deslocamento de famílias e, ou, comunidades. Esses resultados poderiam ser utilizados nos estudos de viabilidade ambiental, EIA/RIMA, elaborados quando da submissão de projetos de barragens à projeção de alternativas ou mesmo de indicadores de impacto socioambiental, no sentido de minimizar os seus efeitos.

Pretendeu-se, portanto, como objetivo geral apresentar discussões a respeito de algumas vertentes relacionadas ao modelo capitalista, sua interface com os grandes projetos de desenvolvimento econômico e seu impacto na qualidade de vida das famílias atingidas. Logo, tiveram-se como objetivos específicos:

- Analisar o desenvolvimento econômico e a modernidade, a partir do discurso que engendra toda relação homem/natureza/desenvolvimento.

- Avaliar os movimentos de desterritorialização e reterritorialização existentes, a partir da construção de hidrelétricas e em detrimento dos valores socioculturais existentes e interesses distintos.

- Apresentar as transformações ocorridas na vida das famílias atingidas pela construção dos empreendimentos hidrelétricos, ilustradas a partir da experiência dos atingidos pela construção de Candonga, MG.

\title{
Procedimentos Metodológicos
}

A fim de revelar as contradições inerentes à modernidade, representada aqui pela implantação da construção da hidrelétrica de Candonga, MG, foi realizado um delineamento descritivo, em que se optou por uma abordagem qualitativa, utilizando-se de entrevistas semiestruturadas, observação direta e documentação fotográfica aliada aos dados provenientes de fontes já publicadas, bem como oriundos dos órgãos ambientais e do próprio processo de licenciamento. No total, foram entrevistadas 23 pessoas 
entre homens e mulheres (adultos, idosos e jovens) de 17 casas diferentes, escolhidas aleatoriamente conforme disponibilidade de horário e interesse pela pesquisa. Vale destacar que as entrevistas foram norteadas por questões abertas; a partir dessas, os entrevistados ficaram livres para falar sobre o reassentamento e seus sentimentos, bem como para relembrar o antigo lugar. No final, os dados oriundos das gravações foram transcritos e, posteriormente, cruzados com os demais. A partir desses foram feitas as análises, segundo os objetivos propostos.

\section{Desenvolvimento e Modernidade: $\mathrm{O}$ discurso que legitima os processos de barragem}

A ideia de modernidade está inteiramente relacionada com o uso da razão, responsável por estabelecer uma estreita relação entre a ação humana e a ordem do mundo moderno. Segundo Touraine (1994), um crítico das questões relacionadas à modernidade, "é a razão que anima a ciência e suas aplicações; é ela também que comanda a adaptação da vida social às necessidades individuais ou coletivas". De acordo com os pensamentos desse autor, a razão conduz a humanidade a agir segundo suas próprias leis, em direção à abundância, felicidade e liberdade.

Essa afirmação foi e é muito discutida e, às vezes, rejeitada pelos críticos da modernidade. A razão, como colocada na afirmação, não se evidencia suficientemente capaz de garantir a felicidade por meio da libertação dos controles tradicionais, da forma como proposta. Ela apenas promove a libertação do tradicionalismo. A afirmação de que o progresso interliga e proporciona esses três objetivos nada mais é do que a ideologia ${ }^{4}$ utilizada para naturalizá-lo como um fenômeno capaz de trazer melhores condições de vida a todos.

De acordo com Martins (2008), a ideia de modernidade está diretamente relacionada ao progresso, aqui entendido como sinônimo de modernização e desenvolvimento ou, segundo Berman (1986), um processo socioeconômico que vai construindo a modernidade. Modernidade é uma característica associada aos países ricos, que disseminam seus padrões, fazendo com que o resto do mundo trave uma verdadeira "busca" pelo status, alcançado por poucos, de ser considerado um país desenvolvido.

Ainda segundo Martins (2008), na América Latina o termo modernidade é inteiramente confundido como oposição ao tradicional, ao que supostamente não faria parte do moderno, dos novos tempos. A modernidade é retratada pelas possíveis transformações que o capitalismo é capaz de criar e pelas possibilidades oferecidas. Ao mesmo tempo, esse autor faz críticas ao residual desse processo, de como ele se apresenta, pois "mais se fala de modernidade do que efetivamente ela o é" 5 . Assim, a modernidade só é quando pode ser, ao mesmo tempo, o moderno e a consciência crítica do moderno. Em países subdesenvolvidos, ela instaura-se pela busca do novo, do moderno, pelo encontro dos ritmos desiguais do desenvolvimento econômico e social, pelo avanço tecnológico, pela acelerada e desproporcional acumulação de capital, pela imensa e crescente miséria globalizante, parte integrante da modernidade (MARTINS, 2008), anunciando o possível, as possibilidades que apresentam para todos, mas que se realizam apenas para alguns.

A modernidade não pode ser entendida como uma simples mudança ou sucessão de acontecimentos; ela nada mais é do que a produção de atividades racionais, científicas, tecnológicas e administrativas (TOURAINE, 1994). Ass transformações ocorridas no mundo, a partir da modernidade, revelam uma realidade que, conforme Giddens (1995), é muito mais complexa e sofisticada se comparada ao passado. As mudanças dizem respeito à interseção entre a globalização e a transformação da vida cotidiana, de modo que o que nela se faz tem consequências globais e o que acontece globalmente tem consequências locais.

A globalização é primordialmente a transformação do tempo, do espaço, da experiência local, não uma coisa só, mas um complicado conjunto de transformações das condições básicas da vida social. Ela não produz necessariamente um mundo mais unificado, ela produz a fragmentação. Esses dois elementos acham-se imbricados um no outro (GIDDENS, 1995, p. 300).

Conforme esse mesmo autor, "modernidade refere-se a um estilo, costume de vida ou organização social que emergiram na Europa a partir do século XVII, e que ulteriormente se tornaram mais ou menos mundiais em sua influência". , 
Ser moderno é viver em um mundo de experiências compartilhadas por todos, é encontrarse em um ambiente que promete aventura, poder, alegria, crescimento, autotransformação e transformação das coisas em redor - mas ao mesmo tempo ameaça destruir tudo o que temos, tudo o que sabemos, tudo o que somos (Berman, 1986, p. 13).

Enfim, ser moderno é fazer parte de um universo onde, como dizia Marx, "tudo que é sólido se desmancha no ar" (LUDWIG, 2008).

Neste momento em que se vive, assiste-se ao triunfo de uma sociedade industrial e capitalista, em que as preferências individuais e escolhas sociais reproduzem, em maior ou menor grau, uma ordem instrumentalmente racional, que tem como referência o mercado. Hoje, forçam-se a reconhecer a imprevisibilidade das ameaças provocadas pelo desenvolvimento técnico-industrial e a procurar modos diferentes de relação com as incertezas (GIDDENS, 2000). Essas ameaças são movidas pelo desejo de mudança, de autotransformação e de transformação do mundo em redor. Para Berman (1986), ser moderno é viver uma vida de paradoxo e contradição. É sentir-se fortalecido pelas imensas organizações burocráticas, que detêm o poder de controlar e frequentemente destruir comunidades, valores, vidas.

É pautado nesses conceitos de modernidade que os grandes projetos de infraestrutura são chamados projetos de desenvolvimento, pois caracterizam o progresso almejado pela modernidade, associado ao desenvolvimento e à busca do status na sociedade global. As construções de usinas hidrelétricas representam empreendimentos que podem ser explicados pelo contexto da modernização capitalista. A busca pela maximização do lucro e por melhorias tecnológicas acarretam investimentos cada vez maiores nesse tipo de empreendimento. Apesar da argumentação em favor da produção de energia elétrica a partir da sua construção, são inquestionáveis os efeitos ambientais e sociais advindos.

Esse tipo de discurso que protagoniza o desenvolvimento a partir da sua esfera econômica se distancia cada vez mais da vida e realidade das pessoas, questionando-se se essa é realmente uma condição favorável para o futuro ou, apenas uma palavra vazia que representa o crescimento a todo e qualquer custo. O distanciamento entre o discurso e a prática evidencia a composição de "planosdiscurso", em que o social e ambiental passam "a esconder ao invés de mostrar. Esconde a direção tomada pelas obras e pelos investimentos que obedecem a um plano não explícito" (MARICATO, 1997).

\section{Hidrelétricas: desterritorilização e reterritorialização}

A construção de projetos hidrelétricos no Brasil teve seu ápice a partir de 1970 com a criação da Eletricidade Brasileira (ELETROBRÁS); o objetivo era propiciar a instalação de tais empreendimentos, vistos como estratégias de desenvolvimento para o processo de industrialização e desenvolvimento do país. Acreditava-se, segundo Sigaud (1988), que os benefícios gerados iriam sobrepor-se aos malefícios; ou seja, ao longo do tempo, os efeitos negativos estariam subordinados a um fator predominante: a questão energética. Para tanto, o discurso ideológico utilizado para legitimar a implantação desses empreendimentos pautava-se não somente na promoção da expansão da economia do país, mas também na sua contribuição para reduzir as desigualdades inter-regionais.

Projetos inovadores, que subsidiavam a modernidade do país, como as construções hidrelétricas, tornaram-se, então, o meio de expansão de novas técnicas e tecnologias de apoio ao crescimento da produção nacional. Embalados pelo discurso ideológico do "desenvolvimento e progresso" (VAINER, 2007; REZENDE, 2008; BERMANN, 2003; ZHOURI 2005), esses projetos se apresentam como essenciais à nação, à região de instalação e às populações ribeirinhas, pois os "redimiriam do atraso". Essa "ideologia de redenção" faz parte do processo de legitimação do projeto e manifesta-se por meio dos constantes discursos dos organismos governamentais e das empresas envolvidas (LINS RIBEIRO, 1985).

Catullo (apud LUDWIG, 2003, p. 67) enfatizou que, tendo em vista esse processo legitimador de discurso positivista, não é difícil entender o pouco compromisso com as populações locais afetadas. Essa posição traz embutida a ideia de que o progresso tem seus custos e que alguém deve pagar por eles; ou seja, os prejuízos existirão e representarão a cota necessária ao desenvolvimento: "um Estado capitalista e moderno pode respeitar as diferenças culturais na medida em que não sejam obstáculos ao desenvolvimento, à modernidade".

Sendo assim, a construção de UHE se dá em detrimento de segmentos sociais vulneráveis, como as populações ribeirinhas e as comunidades étnicas (WCD, 2000; ZHOURI; OLIVEIRA, 2005). Ao 
falarem das vítimas das políticas econômicas que estipulam grandes projetos, Scherer-Warren (apud ROTHMAN, 2002) afirmou que, no Brasil, os prejuízos decorrentes desses empreendimentos recaem sobre os atingidos expropriados urbanos e rurais, os camponeses e as etnias nativas.

A confrontação de interesses entre os atores envolvidos nesse processo é evidente. Para os empreendedores, o projeto representa lucro e investimento; para o governo, incentivos e insumos às atividades produtivas e assim ao desenvolvimento; enquanto para as comunidades atingidas os interesses são outros. É fato que o meio ambiente não é apenas um objeto ameaçado pelo seu esgotamento. Acselrad (2005) relatou que ele é atravessado por diversos sentidos socioculturais e interesses diversificados que compõem o antagonismo anteriormente mencionado. As águas dos rios muitas vezes têm-se apresentado como objeto de uso e apropriação pelas empresas, que veem nesse recurso hídrico fonte geradora de energia, ao mesmo tempo que essas águas representam meio de subsistência para diversas famílias que vivem às suas margens.

Segundo Zhouri et al. (2005), as comunidades atingidas, muitas vezes, não possuem conhecimento real do projeto e dos seus impactos, sendo colocadas no processo como sujeitos passíveis de adaptação e de negociação. Os interesses antagônicos que permeiam o processo acabam por colocar as comunidades atingidas como meras expectadoras do processo, que, por meio de um processo "democrático", busca estabelecer tal empreendimento como essencial ao progresso e à modernidade do país.

Diferentes pesquisadores que trabalham com questões relacionadas às barragens têm considerado que a implantação de projetos hidrelétricos acarreta para a região de instalação a desestruturação de atividades preexistentes, desordenado crescimento populacional, desemprego, marginalização social e degradação ambiental, em vez de contribuir, segundo os discursos utilizados, para reduzir as disparidades regionais, por meio da desconcentração industrial e abertura de frentes de trabalho nas regiões instaladas. Santos (2006) evidenciou ainda mais o discurso de desenvolvimento que acompanha a implantação de grandes hidrelétricas:

Quando nos dizem que as hidrelétricas vem trazer, para um país ou para uma região a esperança de salvação da economia, da integração do mundo, a segurança do processo, tudo isso são símbolos que nos permitem aceitar a racionalidade do objeto que, na realidade ao contrário, pode exatamente vir destroçar a nossa relação com a natureza e impor relações desiguais (SANTOS, 2006, p. 217).

É possível destacar as consequências negativas desses empreendimentos sobre os atingidos, como: perdem o investimento feito por uma ou várias gerações na propriedade, a segurança representada pelo espaço construído ou vivido, o sentido de lugar, ou seja, além das perdas materiais, são inquestionáveis as perdas sociais e simbólicas. A ruptura das relações de vizinhança, de parentesco, de comunidade e perdas de bens culturais constitui exemplos do processo de desenraizamento das populações que são obrigadas a sair de seus territórios.

A migração forçada aparece como uma saída para viabilizar a reprodução da força do capital. A palavra "migrar" vem constituir-se como "fuga" (SCHERER-WARREN, 1990) não apenas no sentido de mudança de um espaço físico para outro, mas com sentidos múltiplos, com base em ruptura de representações simbólicas e do espaço como apropriado e construído socialmente.

A questão da migração remete à desterritorialização, que, conforme Souza (1995), supõe a exclusão do grupo que anteriormente se apropriava daquele espaço. Já como assinalou Haesbaert (2011), seria fruto do enfraquecimento do controle exercido sobre determinado espaço, resultando na mobilidade de pessoas, bens materiais, capitais ou informações. É com base nesse ínterim que o território se configura como um campo de forças ou "teia de relações sociais" (SOUZA, 1995; RAFFESTIN, 1993; HAESBAERT, 2011), demarcado pelas disputas. A relação dos sujeitos com seu território revela sentimentos, valores e referências transmitidos pelas gerações que construíram sua própria cultura ${ }^{6}$, seu modo de vida e atribuíram, para além do valor material, um valor simbólico àquele lugar. $\mathrm{O}$ território vai muito além da simples dimensão objetiva da reprodução de necessidades básicas e das relações de poder, ao incluir outra dimensão - subjetiva e simbólica, identitária, afetiva e cultural - fundada pela prática social.

De modo geral, o território é entendido como resultado de um espaço histórico de construção por agentes sociais, que lhe imprimem suas características socioculturais. Ainda assim, o território é o 
resultado da interação entre as relações sociais e de poder (SOUZA, 1995) estabelecida em determinado espaço e o controle desse. Essas relações abarcam tanto as relações de dominação quanto as de apropriação, pois, conforme Haesbaert (2011), o território tem a ver com o poder, mas não apenas ao tradicional "poder político". Esse estudioso disse a respeito tanto do poder no sentido mais concreto quanto do poder no sentido simbólico, de apropriação. Lefebvre (apud HAESBAERT, 2011, p. 35) distinguiu apropriação de dominação: o primeiro sendo um processo mais simbólico, carregado do vivido, do valor do uso; e, o segundo, mais concreto, funcional e vinculado ao valor de troca.

A territorialização de hidrelétricas implica em desterritorialização e a essa segunda remete-se o processo de reterritorialização, que sugere a incorporação de novos territórios; ou seja, a construção de nova territorialidade por parte do grupo desterritorializado. Dessa forma, territorializam-se hidrelétricas e, ao mesmo tempo, des/re/territorializam-se populações. As famílias desterritorializadas perdem e, ou, alteram seus referenciais espaciais, ocasionando o desenraizamento e esfacelamento da identidade social e coletiva dos sujeitos ${ }^{7}$. Surge a necessidade de construir novos territórios, reconstruindo-se a si mesmas no espaço, seja sob a vontade delas ou não. Esse processo de desterritorialização/reterritorialização das famílias faz parte da racionalidade econômica do modelo capitalista, que faz do solo mercadoria (LUDWIG, 2008).

Frente a esse processo, Cavalcanti (2002) enfatizou o desenraizamento causado pelo desencontro do ser naquilo que lhe é dado tradicionalmente como substancial para pertencer a um grupo social. Entretanto, a necessidade de territorializar leva ao enraizamento, considerado, por esse mesmo autor, como uma das mais difíceis necessidades do ser humano a ser definida. Cada "indivíduo tem uma raiz por sua participação real, ativa e natural na existência de uma coletividade que conserva vivos certos tesouros do passado e certos pressentimentos do futuro" (MEDEIROS, 2007). Além disso, os indivíduos encontram também dentro de sua própria cultura espaços diferenciados, aos quais se articulam, constroem e reconstroem-se referências de uma forma permanente, tanto para si como para o outro.

O processo de desterritorialização marca a perda da identidade territorial existente naquele espaço/ lugar. Parte-se do pressuposto que "toda a identidade territorial é uma identidade social definida fundamentalmente através do território"; ou seja, dentro de uma noção de apropriação que se dá tanto no campo das ideias quanto no da realidade concreta (HAESBAERT, 2011). A reterritorialização surge como uma territorialização precária, pois apesar de habitar ${ }^{8}$ (LEFEBVRE apud HAESBAERT, 2011, p.80) determinado espaço, o sujeito desterritorializou-se de seu modo de vida, de seus valores culturais e sociais. Essas novas territorialidades emergem da necessidade de reterritorializar determinados grupos sociais, ainda que por meio de um processo instável de reapropriação de vida, que muitas vezes surge negligenciando a dimensão socioambiental e espacial inerente.

Nos casos nos quais o espaço/lugar se torna alvo de projetos hidrelétricos, esse vira palco de luta pelo seu uso. A implantação do empreendimento leva à desterritorialização/reterritorialização das famílias, as quais, transferidas territorialmente, são, muitas vezes, impostas a novo estilo de vida. O espaço ora apropriado por essas famílias vira palco da dominação capitalista, do uso e poder dessa, ao passo que os desterritorializados são levados a se apropriarem de novos espaços e de dotá-los de sentido. Assim, ao discutir e analisar essas mudanças, não se tem a pretensão de anular a importância, já consolidada, dessas obras contextualizadas no modelo de desenvolvimento adotado pelo país. Procura-se sim, evidenciar como a modernidade espelha contradições, apresentando um caso concreto de empreendimento, símbolo de modernidade.

\section{Conflitos e sujeitos: o caso da Hidrelétrica Candonga, MG}

Quando o processo de des/reterritorialização se efetiva concretamente no espaço, como acontecido na usina já concluída de Candonga (Zona da Mata mineira), evidenciam-se as contradições que emergem do processo de deslocamento/reassentamento vivido pelas famílias atingidas, especificamente nesse caso, as antigas moradoras do distrito de São Sebastião do Soberbo, Antiga Soberbo/Nova Soberbo. No estudo desenvolvido, pode-se perceber que a implantação da Hidrelétrica Candonga revela a lógica da racionalidade capitalista, pautada na busca do "desenvolvimento e progresso". No contexto da modernidade e da necessidade cada vez maior de energia para manter e acelerar o crescimento do país, esses empreendimentos são impostos às comunidades ribeirinhas, que compulsoriamente são retiradas de suas terras e realocadas em outro espaço. O deslocamento, desejado ou não, rompe costumes, práticas sociais e identidades, além de desestruturar modos de vida. 
Como o ocorrido com os atingidos pela UHE Candonga, o deslocamento, embora mascarado pelo desejo de uma vida melhor, não foi capaz de reproduzir os modos e condições de vida das famílias, como na Antiga Soberbo. A migração, que em algum momento pode ter representado possibilidades de novas oportunidades para aqueles que se deslocaram para fora do distrito, posteriormente passou a se apresentar como a única alternativa para as famílias, obrigadas a sair de suas terras para dar lugar ao lago da barragem.

Das falas dos moradores foi possível perceber que uns, os quais a princípio desejaram a barragem, tinham a expectativa de sair do antigo distrito, "daquele lugar feio, horroroso", do lugar que "parecia uma roça". Outros, apesar de instigados com as novas oportunidades oferecidas, ficaram inseguros quanto ao futuro, o que geraria inclusive disputas por interesses entre os próprios atingidos. O novo distrito prometido viria a representar um distrito industrial, com condições de trazer melhores condições de vida e trabalhistas para o município e região (BARROS e SYLVESTRE, 2004). No entanto, aos poucos outra realidade foi sendo percebida pela comunidade. Muitas das promessas feitas não foram cumpridas, fazendo com que o processo de negociação se tornasse tenso e conflituoso. Projetos como o da construção de barragens muitas vezes colocam as famílias em situações de risco, pois criam a sensação de insegurança, tendo em vista que o novo é desconhecido pelos moradores, gerando assim conflitos por interesses diversos.

Por terem construído suas vidas naquele lugar, os moradores falaram do passado com emoção, apreendendo aspectos que vão muito além da paisagem e remetendo às relações e ao estilo de vida que tinham antes da barragem. Anteriormente, a reprodução econômico-social das famílias se fazia por meio do trabalho na terra, da vida no campo, do garimpo e da pesca. Embora reconheçam as dificuldades existentes em tais atividades, essas lhes proporcionavam uma vida simples, porém com menor dependência externa, uma vez que a subsistência era garantida por aquilo que era plantado e colhido.

Nova Soberbo se apresentou como a possibilidade de uma vida mais citadina, com elementos que marcam a vida urbana e proporcionam conforto e "melhor padrão de vida". Na fala de alguns atingidos percebeu-se a recusa do rural, que muitas vezes é relacionado às dificuldades vividas, à poeira das estradas de chão, ao barro nos tempos de chuva, às casas simples sem perspectivas de melhorias, que caracterizavam a espacialidade do antigo lugar. Como observado na figura 1, essas características do antigo lugar se revestem de significados negativos ao tornar-se um meio de comparação com Nova Soberbo. Elementos peculiares da espacialidade de Nova Soberbo conferem significados positivos ao novo local: as moradias, o asfalto, os equipamentos urbanos, a facilidade do deslocamento, entre outros. Contudo, os seus moradores ainda fazem questão de falar sobre o processo de deslocamento.

O processo de deslocamento foi permeado por conflitos, representados por interesses antagônicos: de um lado, os empreendedores, interessados no uso e na apropriação do espaço para fins particulares; de outro, os atingidos, os quais, acreditando nas promessas feitas, desejaram o projeto, que, por ora, ainda não trouxe os resultados esperados. Como observou Martins (2008), é a modernidade que anuncia o possível, embora não o realize, colocando uma comunidade inteira incluída de modo excludente no contexto modernizante da economia capitalista.

Os conflitos aqui revelados se vinculam às indenizações (irrisórias, injustas) e à carência de avaliação das consequências do reassentamento para os atingidos, seja por parte do empreendedor ou de uma instituição pública responsável. Observou-se que as indenizações e reassentamentos causam diversos conflitos, especialmente de adaptação, identidade, valores e significados, estrutura, expectativas, interesses, atribuição e legitimidade.

A desinformação da população, característica revelada pelos atingidos durante as entrevistas, não foi apenas com relação ao futuro, mas também a todo o processo de construção e operação do empreendimento. A incapacidade de perceber as ameaças deve-se à forma como os sistemas peritos ${ }^{9}$ agiram. Apoiados no conhecimento e na experiência sobre o assunto, apoderaram-se da ausência desse conhecimento por parte da população, sobrepondo momentos e conquistando as licenças necessárias para implantar o empreendimento.

Dependendo do observador, os atingidos são caracterizados como beneficiários do processo, em vez de serem considerados "atingidos". A nova vida proporcionada pela empresa se apresenta como um mérito concedido a essas famílias, que anteriormente ao empreendimento viviam em condições espaciais consideradas inferiores. O espaço, construído para abrigar os atingidos pela barragem, possibilita uma vida artificialmente planejada, diferente de tudo que se vivia no antigo lugar. Nesse contexto, é a racionalidade da ordem global que impõe a todos uma forma única de viver e que diante disso é desterritorializadora. 

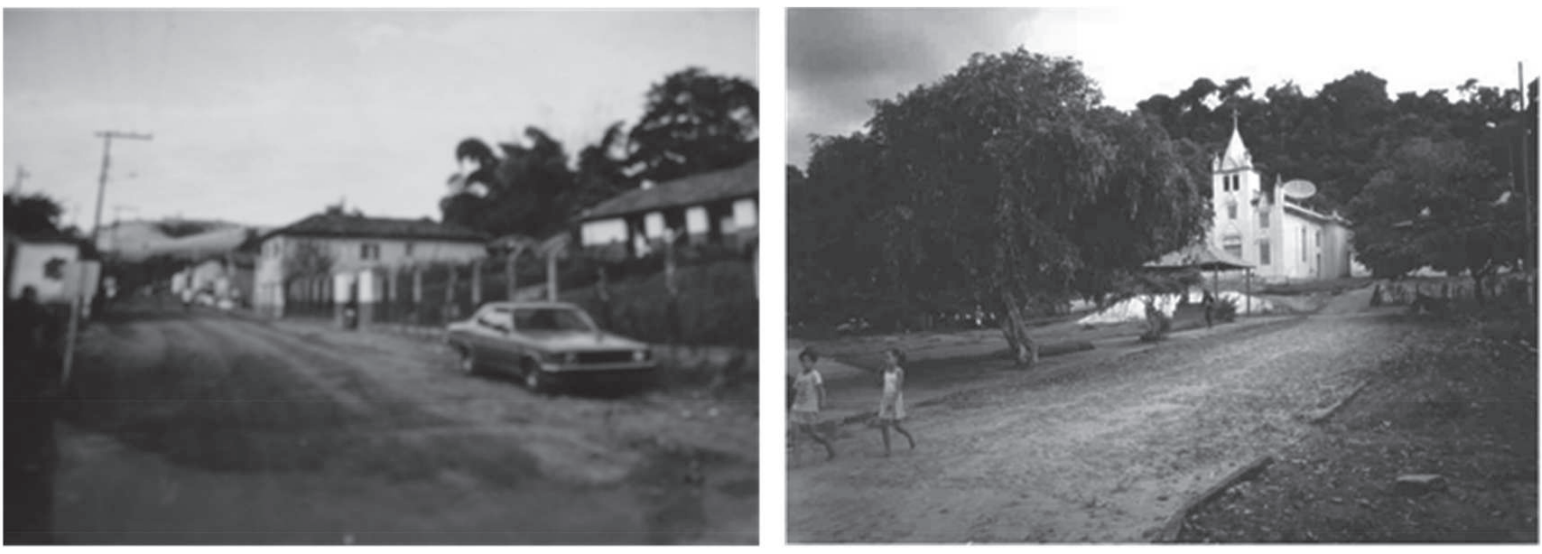

Fonte: Arquivo MAB/ Ponte Nova
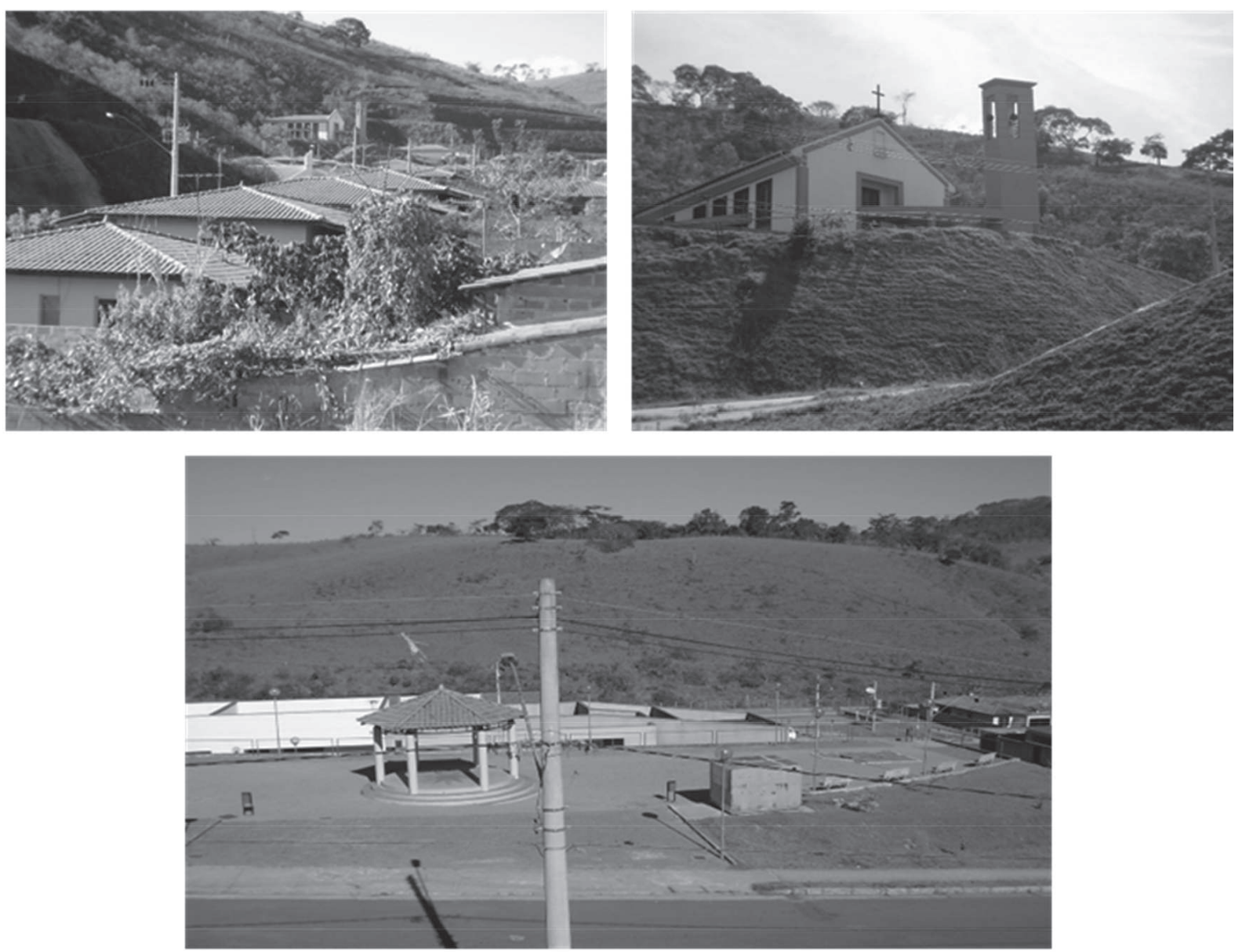

Fonte: Arquivo da pesquisadora - fotos tiradas durante o trabalho de campo.

Figura 1 - Imagens 1 e 2 apresentando a Antiga Soberbo e Imagens 3, 4 e 5 apresentando a Nova Soberbo. Evidencia-se as diferenças estruturais do antigo com o novo distrito.

Nos quatro anos seguidos após a implantação do empreendimento, os atingidos viveram alimentados de promessas e ilusões. A realidade na comunidade muito difere da vida anterior à barragem e demonstra que um salto na qualidade de vida desses moradores é algo ainda remoto, principalmente para os jovens, os quais, sem maiores perspectivas no local, continuam reproduzindo a vida da Antiga Soberbo - migrando para os centros urbanos. A ausência do Plano de Reativação Econômica, como proposto, e as dificuldades das famílias de conseguirem produzir e reproduzir econômica, social e culturalmente inviabilizam a adaptação dos moradores, os quais, após esses anos, ainda vivem em total dependência do consórcio. Esse, por sua vez, entregou o distrito para o município; 
contudo, é de suma importância ressaltar que tramita em justiça uma luta pelo processo de reativação econômica que dê mais segurança e garantia de sobrevivência aos moradores reterritorializados.

Muito do que se espera do futuro pode ser captado na fala dos atingidos, os quais, sem esperança, não remetem a um futuro próspero. "Eu acho que daqui uns anos isso aqui não vai ser nada, só gente velha!" e "daqui uns cinco a 10 anos, essas casas vão estar tudo caindo, muita gente passando necessidade, como já tem hoje" são falas que apresentam uma futura deterioração do que hoje é considerado um distrito bonito e com características mais urbanizadas. O futuro aqui projetado não se diferencia muito da realidade que existia na Antiga Soberbo, antes da chegada do empreendimento: um distrito marginalizado e deteriorado pela ação do tempo e pela falta de recursos dos seus moradores em preservar as antigas construções existentes, muitas delas herdadas de parentes já falecidos.

\section{Considerações Finais}

Este trabalho apresenta as contradições do processo de modernização do país, evidenciando por meio dos processos de desterritorialização/reterritorialização que engendram a implantação de construção de hidrelétricas a forma como o moderno se impõe sobre o tradicional, transformando o atrasado em atual, o antigo em novo, mas não sendo capaz de incluir aqueles que já são excluídos da modernidade. Nova Soberbo é falada a partir das lembranças da Antiga Soberbo, pelos seus modos e pelas suas condições de vida e pelo que foi perdido no decorrer do processo. Pelas falas dos moradores parece haver um caráter idílico, romântico, quando esses se remetem à antiga localidade de residência. Esse fato é evidente, visto que eles remetem a um lugar importante para suas vidas e que não existe mais. O processo de deslocamento/assentamento vivido marca a chegada a um espaço novo, que, almejado pela comunidade, impôs a desterritorialização e reterritorialização. Um dos desafios é fazer com que a memória e a vida dessas pessoas deem conta de preencher os espaços de significados sociais perdidos a partir desse processo vivido. Do antigo lugar ficaram apenas as lembranças.

Pôde-se perceber que nesse processo o espaço é visto e apropriado em razão do capital. Sendo assim, a ação do poder hegemônico remete a um espaço aniquilado e empobrecido para o pleno uso e ao mesmo tempo formalizado e mobilizado para a troca, como mercadoria. Observou-se que de um lado tem-se o processo de re/produção capitalista do espaço com seus interesses e anseios pela modernidade e progresso e de outro os "atingidos" ameaçados e marcados pelas perdas/ganhos decorrentes. É a partir desse processo que surgem os conflitos e as tensões, remetendo, necessariamente, às análises das contradições aqui apresentadas.

Em relação ao resultado desta pesquisa, tornou-se visível que a implantação de um projeto hidrelétrico gera consequências muito maiores do que aquelas previstas nos seus estudos de impactos. Esses projetos rompem com costumes, práticas sociais e modos de vida em razão do uso e da apropriação do espaço para fins particulares. Assim, acreditando na complexidade desse tema e na atual repercussão sobre os novos preceitos do governo brasileiro em acelerar o crescimento do país, fica aqui a reflexão sobre os resultados colhidos e um convite a repensar as formas como esses empreendimentos são implantados. Sem pretender anular a sua importância, notou-se que as consequências desses processos são provenientes da busca pelo lucro, que impede maiores preocupações com o futuro daqueles que são atingidos. Repensar tais formas significa mais custos ao empreendedor, que parece ainda não ter sensibilidade para compreender a complexidade que envolve um processo deslocamento/reassentamento.

\section{Referências Bibliográficas}

ACSERALD, H. Apresentação. In: ZHOURI, A. et al. (Eds.) A insustentável leveza da política ambiental - desenvolvimento e conflitos socioambientais. Belo horizonte: Autêntica, 2005.

BARROS, J. N.; SYLVESTRE, Marie-Eve (orgs.). Atingidos e barrados: as violações e direitos humanos na hidrelétrica Candonga. Rio de Janeiro: Justiça Global, 2004. 112p.

BENJAMIN, C. e RIBEIRO, R. T. Descaminhos do setor elétrico, ou o hospício Brasil. Economia e política econômica. Rio de Janeiro: UERJ, 2004. 14p. Disponível em: < http://www.contrapontoeditora.com.br/ arquivos/artigos/200709271802240.Hospicio\%20do\%20brasil.pdf>. Acesso em: 25 ago. 2014.

BERMAN, M. Tudo que é sólido se desmancha no ar: a aventura da modernidade. São Paulo: Companhia das Letras, 1986. 
BERMANN, C. Energia, patrimônio ambiental e a sustentabilidade no Brasil. In: RIBEIRO, W. C. (Org.). Patrimônio ambiental brasileiro. São Paulo: EDUSP/IDESP - Imprensa Oficial de São Paulo, 2003. p. $243-282$.

BRASIL, Agência Nacional e Energia Elétrica. Atlas de energia elétrica do Brasil. 3. ed. Brasília, 2008.

CAVALCANTI, H. O desencontro do ser e do lugar: a migração para São Paulo. In: BURITY, J.A. (org.). Cultura e identidade - perspectivas multidisciplinares. Rio de Janeiro: DP\&A, 2002.

DAMIANI, A. As contradições do espaço: da lógica (formal) à (lógica) dialética, a propósito do espaço. In: DAMIANI, A.; CARLOS, A. F.; SEABRA, O. C. de L. (Orgs.). O espaço no fim de século: a nova raridade. São Paulo: Contexto, 2001. p. 48-66.

GEERTZ, Clifford. A interpretação das culturas. 1 ed. 13 reimpre. Rio de Janeiro: LTC, 2008.

GIDEENS, A. Conversas com Anthony Giddens: o sentido da modernidade. Rio de Janeiro: Editora FGV, 2000. 156 p.

Entrevista com Anthony Giddens. Estudos Históricos. Rio de Janeiro, v. 8, n. 16, p. 291-305, 1995. Disponível em: <http:/ / bibliotecadigital.fgv.br/ojs/index.php/reh/article/view/2002/1141>. Acesso em: 3 mar. 2008.

HAESBAERT, R. O mito da desterritorialização: do "fim dos territórios" à multiterritorialidade. 6 ed. Rio de Janeiro: Bertrand Brasil, 2011. 396 p.

LIMONAD, Ester. O território em tempos de globalização. In: etc, espaço, tempo e crítica. Revista Eletrônica de Ciências Humanas, Sociais e outras coisas. Rio de Janeiro, vol. 1. n 2, p. 39 - 52, 2007. Disponível em: <http://www.uff.br/etc/UPLOADs/etc\%202007_2_4.pdf>. Acesso em: 16 set. 2014.

LINS RIBEIRO, G. S. Proyectos de gran escala: hacia um marco conceptual para el análisis de uma forma de producción temporária. In: BARTOLOMÉ, L. I. (Ed.). Relocalizados: antropologia social de las problaciones desplazadas. Buenos Aires: Ediciones DEL IDE, n.3, 1985.

LUDWIG, M. P. Para além da paisagem: a modernidade que ameaça submergir o lugar. In: ROTHMAN, F. (Ed.),Vidas alagadas: conflitos socioambientais licenciamento e barragens. Viçosa-MG: UFV, p. 235253, 2008.

Descortinando a paisagem - a construção social do espaço e o sentido de lugar: uma comunidade rural da Zona da Mata de Minas Gerais nos umbrais do Século XXI. 2003. 239 f. Tese (Doutorado em Arquitetura e Urbanismo) - Universidade de São Paulo, São Paulo, 2003.

MAB. Hidrelétricas no Rio Madeira: energia para quê e para quem? Rondônia: Cartilha de estudo do MAB. 2007, 24 p.

MARICATO, Ermínia. Enfrentando desafio: a política de habitação e desenvolvimento urbano da Prefeitura de São Paulo, 1989/1992. 1997. 116 f. Tese (Livre-Docência) - Faculdade de Arquitetura e Urbanismo, Universidade de São Paulo, São Paulo, 1997

Martins, J de S. A sociabilidade do homem simples: cotidiano e história na modernidade anômala. 2. ed. Revisada e ampliada. São Paulo: Contexto, 2008. 176 p.

Reflexão crítica sobre o tema da exclusão social. In: A sociedade vista do abismo: novos estudos sobre exclusão, pobreza e classes sociais. Rio de Janeiro: Vozes, 2003.

MEDEIROS, R. M. V. Re-territorialização e identidade. o significado dos assentamentos para a economia dos municípios: os casos de Hulha Negra, Aceguá e Candiota na campanha gaúcha (RS). In: COLOQUIO INTERNACIONAL DE GEOCRÍTICA, 9, 2007, Porto Alegre: UFRS, Los problemas del mundo actual. Soluciones y alternativas desde la geografía y las ciencias sociales. Disponível em: <http:// www.ub.edu/geocrit/9porto/rosamed.htm>. Acesso em: 25 set. 2014.

MESZÁROS, I. Para além do capital: rumo a uma teoria da transição. São Paulo: Boitempo, 2002. $1104 \mathrm{p}$. 
RAFFESTIN, Claude. Por uma geografia do poder. Tradução de Maria Cecília. França. São Paulo: Ática, 1993.

REZENDE, L. P. Dano moral e licenciamento ambiental de barragens hidrelétricas. Curitiba: Juruá, 2008.

ROTHMAN, F. D. Política ambiental e lutas de resistência a barragens em Minas Gerais: um estudo de caso. Raízes. Campina Grande, PB, v. 21, n. 1, p.45-52, 2002.

SANTOS, M. A natureza do espaço: espaço e tempo, razão e emoção. São Paulo: HUCITEC, 4 ed., 2006.

SCHERER-WARREN, I.; REIS, M. J. BLOEMER, N. M. Alto Uruguai: migração forçada e reatualização da identidade camponesa. Travessia Revista do Migrante. São Paulo, v. 2, n.6, jan/ abril, 1990.

SIGAUD, L. M. Implicações políticas e sociais de grandes projetos hidrelétricos sobre as populações indígenas e camponesas. Instituto de estudos avançados. Coleção documentos, série ciências ambientais. São Paulo: USP, n.16, mar, 1994.

Efeitos de grandes projetos hidrelétricos: as barragens de Sobradinho e Machadinho. In: ROSA, L. P.; SIGAUD, L.; MIELNIK, O. (Org.). Impactos de grandes projetos hidrelétricos e nucleares: aspectos econômicos, tecnológicos, ambientais e sociais. São Paulo: Marco Zero, p. 83-166, 1988.

SILVEIRA, Caio Márcio; Reis, Liliane da Costa. Desenvolvimento local: dinâmicas e estratégias. Rio de Janeiro: RITS, 2001.

SOUZA, M. O território: sobre o espaço e poder, autonomia e desenvolvimento. In: CASTRO, I. et al. (Orgs.). Geografia: conceitos e temas. Rio de Janeiro: Bertrand Brasil, 1995.

TOURAINE, A. Crítica da modernidade. Elia Ferreira Edel (Trad.). Petrópolis-RJ: Vozes, 1994. 390 p.

VAINER, C. Recursos hidráulicos: questões sociais e ambientais. Estudos Avançados. São Paulo, v. 21, n. 59, São Paulo, jan/abr, 2007.

ZHOURI, A. et al. Uma sociologia do licenciamento ambiental: o caso das hidrelétricas em Minas Gerais. In: ZHOURI, A., et al. (Orgs.). A insustentável leveza da política ambiental - desenvolvimento e conflitos socioambientais. Belo Horizonte: Autêntica Editora, p. 89-116, 2005.

; OLIVEIRA, R. Paisagens industriais e desterritorialização de populações locais: conflitos socioambientais em projetos hidrelétricos. In: ZHOURI, A., et al. (Orgs.). A insustentável leveza da política ambiental - desenvolvimento e conflitos socioambientais. Belo Horizonte: Autêntica Editora, p. 49-64, 2005.

WORLD COMMISSION ON DAMS - WCD. Barragens e desenvolvimento: um novo modelo para tomada de decisões. Relatório da comissão mundial de barragens. London: Earthscan Publications, 2000.

Recebido para publicação em 15/1/2016 e aprovado em 10/8/2016.

\footnotetext{
${ }^{4}$ Desde o século XIX, em razão do crescente ritmo de integração do sistema mundial, se passou a requerer e utilizar uma ideologia que poderia dar sentido às posições desiguais do sistema, como também fosse capaz de promover aos povos situados em condições de nível inferior um "entendimento" sobre a situação deles e fazêlos acreditar que existia uma saída para a situação de "atraso". Segundo Lins Ribeiro (1992), "a terminologia desenvolvimento envolve o uso de metáforas que se referem ao espaço ou a ordem de maneira hierárquica: desenvolvimento/ subdesenvolvimento, avançado/ atrasado, Primeiro Mundo/ Terceiro Mundo, etc." ${ }^{5}$ José de Souza Martins diz que a modernidade na América Latina, especialmente no Brasil, recebe um tom que não é o seu, não é a sua expressão mais pura, fina. Apresentar-se-á o que ele diz acerca disto: "a modernidade nos chega, pois pelo seu contrário e estrangeira como expressão do ver e não como expressão do ser, do viver e do acontecer. Chega como uma modernidade epidêmica e desconfortável sob a forma do fardo nas costas do escravo negro ele mesmo negação do capital e do capitalismo, embora agente humano e desumanizado do lucro naquele momento histórico" (2008, pg. 24).

${ }^{6}$ Geertz (2008) definiu a cultura como o sistema de símbolos significantes partilhados socialmente, os quais sustentam a construção de mundo dos grupos sociais e não apenas padrões concretos de comportamento - costumes, usos, tradições, hábitos. Para o autor, a cultura é um conjunto de "modelos de" representação do mundo e da realidade, mas também um conjunto de "modelos para" agir no mundo (padrões, guias para a ação).

${ }^{7}$ Apesar de Martins fazer referência aos migrantes, considerando que os atingidos deverão se deslocarem, torna-se pertinente a observação do autor: "Nem todos os migrantes são um problema social, mas na migração está envolvido, sem dúvida, um problema social. Onde está o problema social? Está na reinclusão, no problema da dificuldade da inclusão, na forma patológica da inclusão" (MARTINS, 2003, p.127, grifos das autoras).

${ }^{8}$ Lefebvre opõe os conceitos de habitar e habitat: “No final do século XIX, um pensamento (se é possível dizer) urbanístico, tão forte quanto inconscientemente redutor, pôs de lado e literalmente entre o parêntesis o habitar. Ele concebeu o habitat, função simplificada, restringindo o ser humano a alguns atos elementares: comer, dormir, reproduzir-se. Nem ao menos se pode dizer que os atos funcionais elementares sejam animais. A animalidade tem uma espontaneidade mais complexa" (LEFEBVRE apud HAESBAERT, 2011, p.80).

${ }^{9}$ Aqui os sistemas peritos são descritos pelos engenheiros, doutores e estudiosos que trabalham na empresa construtora do empreendimento. Nos termos de Giddens (2000), esses sistemas peritos representam aquelas pessoas dotadas de competência profissional que, por meio da informação técnica, ganham a confiança dos envolvidos no processo, os atingidos.
} 